\title{
Asymmetric synthesis of cyclopropanes by reaction of (2E,SS)-(+)-4,4-diethoxy-2-[(4-methylphenyl)sulfinyl]but-2- enenitrile and 2-methoxyfuran
}

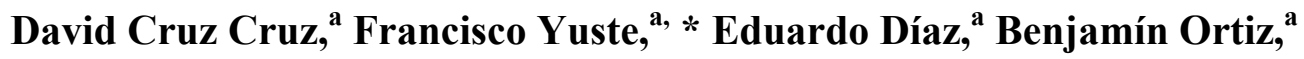 \\ Rubén Sánchez-Obregón, ${ }^{a}$ Fernando Walls, ${ }^{a}$ and José L. García Ruano ${ }^{\text {b, * }}$ \\ ${ }^{a}$ Instituto de Química, Universidad Nacional Autónoma de México, Circuito Exterior, Cd. \\ Universitaria, Coyoacán 04510, México D. F. \\ ${ }^{b}$ Departamento de Química Orgánica (C-I), Facultad de Ciencias, Universidad Autónoma de \\ Madrid. Cantoblanco, 28049-Madrid, Spain \\ E-mail:yustef@servidor.unam.mx; joseluis.garcia.ruano@uam.es
}

\section{Dedicated to Professor Eusebio Juaristi on the occasion of his $55^{\text {th }}$ birthday} (received 01 Apr 05; accepted 18 May 05; published on the web 21 May 05)

\begin{abstract}
The reaction of 2-methoxyfuran with the 2-sulfinylacrylonitrile $\mathbf{1}$ provides a route to the asymmetric synthesis of cyclopropanes. Problems associated with the separation of the two formed diastereoisomers and the epimerization observed in desulfinylation reactions are described.
\end{abstract}

Keywords: Asymmetric cyclopropanation, vinyl sulfoxides, sulfinylcyclopropanes

\section{Introduction}

The stereoselective construction of optically pure functionalized cyclopropanes is a matter of great interest ${ }^{1}$ since these structural moieties are present in many natural and unnatural products exhibiting significant biological activities. ${ }^{2}$ Additionally, cyclopropanes can be used as chiral three-carbon building blocks ${ }^{3}$ for synthesizing other more complex substances due to the chemical versatility of this small rings. ${ }^{4}$ Particularly, sulfinyl substituted cyclopropanes are of synthetic interest because several sulfur mediated ring opening reactions have been developed. ${ }^{5}$ The described methods for the asymmetric synthesis of functionalized sulfinylcyclopropanes are based on a stereoselective Michael addition of nucleophiles to enantiomerically enriched vinyl sulfoxides followed by ring closure of the initial Michael adduct. ${ }^{1 \text {, }}{ }^{6}$ In this field, we have recently reported the reaction of some sulfur ylides with 2-sulfinylbutenolides. ${ }^{7}$ These reactions provide bicyclic sulfinylcyclopropanes in highly stereoselective way, but the attempts to 
eliminate the sulfinyl group by reductive desulfurization were unfruitful. Much easier was the hydrogenolysis of the C-S bond from monocyclic sulfinylcyclopropanes resulting in the pyrolysis of sulfonylpyrazolines. ${ }^{8}$ This observation suggested the convenience of using acyclic vinyl sulfoxide as electrophiles in their cyclopropanation reactions with nucleophiles. In this context, we were interested in the reported nucleophilic behavior of 2-methoxyfuran when it is confronted with good Michael acceptors to yield racemic cyclopropanes according to a Michael induced ring closure cyclopropanation. ${ }^{9}$ On this basis we reasoned that reactions using properly activated chiral vinyl sulfoxides as electrophiles and 2-methoxyfuran as nucleophile could provide a new entry to the synthesis of optically active cyclopropanes. With the aim of exploring the scope of this method we chose (2E,SS)-(+)-4,4-diethoxy-2-[(4-methylphenyl)sulfinyl]but-2enenitrile (1) as the starting sulfoxide, because of its acyclic structure as well as our interest in the chemical behavior of sulfinylacrylonitriles. ${ }^{10}$ Moreover, the stereoselectivity control this sulfoxide had shown in Diels-Alder reactions with cyclopentadiene, ${ }^{10 e}$ suggested it could be analogously efficient in reactions with nucleophiles. In this paper we report the results obtained in the study of their reactions with 2-methoxyfuran under different conditions, as well as some transformations providing desulfinylated cyclopropane derivatives. Details concerning the configurational assignment of the resulting adducts and a mechanistic proposal explaining the stereochemical results are also presented.

\section{Results and Discussion}

The starting optically pure (2E,SS)-(+)-4,4-diethoxy-2-[(4-methylphenyl)sulfinyl]-but-2enenitrile (1) was obtained following a previously described synthetic route. ${ }^{10 \mathrm{e}}$ The results obtained in reactions of 2-methoxyfuran with diethylacetal 1 using $\mathrm{CH}_{2} \mathrm{Cl}_{2}, \mathrm{CH}_{3} \mathrm{CN}$ or $\mathrm{CH}_{3} \mathrm{NO}_{2}$ as solvents, under thermal and catalytic conditions, are collected in Table 1. All reactions were performed at $25^{\circ} \mathrm{C}$. Only two of the eight possible adducts were formed in all cases. We first carried out the reaction of 1 with an excess of 2-methoxyfuran (6 equiv.) in $\mathrm{CH}_{2} \mathrm{Cl}_{2}$ for $24 \mathrm{~h}$ and obtained an inseparable mixture of sulfinylcyclopropanes $\mathbf{2 a}$ and $\mathbf{2 b}$ in 80:20 ratio (41 \% yield after flash chromatography, entry 1 ). The use of more polar solvents such as $\mathrm{CH}_{3} \mathrm{CN}$ (entry 2) or $\mathrm{CH}_{3} \mathrm{NO}_{2}$ (entry 3) slightly decreases the stereoselectivity. The reaction time is significantly lower in $\mathrm{CH}_{3} \mathrm{NO}_{2}$. The addition of Eu(fod) 3 increases the reactivity only in $\mathrm{CH}_{3} \mathrm{CN}$ (entry 5), but the stereoselectivity is significantly decreased in all the solvents (entries 4, 5, and 7). The best yield was obtained in $\mathrm{CH}_{3} \mathrm{CN}$ under $\mathrm{Eu}(\mathrm{fod})_{3}$ catalysis without using an excess of the diene (70\%, entry 6) and the resulting 60:40 mixture of $\mathbf{2 a / 2 b}$ has been used for further explorations. In $\mathrm{CH}_{3} \mathrm{NO}_{2}$, decreasing of the excess of diene did not have the same influence (entry 8). The use of $\mathrm{ZnBr}_{2}$ as catalyst produces the inversion of the diastereofacial selectivity (entries 9-11) but the yields were very low due to the formation of decomposition products. 
Table 1. Reactions of $\mathbf{1}$ with 2-methoxyfuran at $25^{\circ} \mathrm{C}$<smiles></smiles>

1

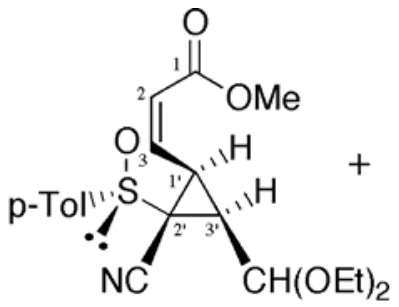

2a

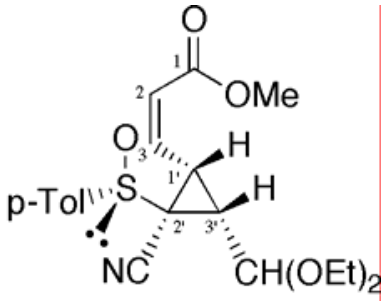

2b

\begin{tabular}{|c|c|c|c|c|c|c|}
\hline Entry & Solvent & $\begin{array}{c}2- \\
\text { Methoxyfuran } \\
\text { (equiv.) }\end{array}$ & $\begin{array}{l}\text { Lewis acid } \\
\text { (1.5 equiv.) }\end{array}$ & $\mathrm{t}(\mathrm{h})$ & $2 \mathrm{a} / 2 \mathrm{~b}$ ratio $^{\mathrm{a}}$ & Yield (\%) \\
\hline 1 & $\mathrm{CH}_{2} \mathrm{Cl}_{2}$ & 6 & & 24 & $80 / 20$ & 41 \\
\hline 2 & $\mathrm{CH}_{3} \mathrm{CN}$ & 6 & & 39 & $72 / 28$ & $--^{c}$ \\
\hline 3 & $\mathrm{CH}_{3} \mathrm{NO}_{2}$ & 6 & & 1 & $75 / 25$ & 50 \\
\hline 4 & $\mathrm{CH}_{2} \mathrm{Cl}_{2}$ & 6 & $\mathrm{Eu}(\text { fod })_{3}$ & 24 & $60 / 40$ & 47 \\
\hline 5 & $\mathrm{CH}_{3} \mathrm{CN}$ & 6 & $\mathrm{Eu}(\text { fod })_{3}$ & 1 & $60 / 40$ & 30 \\
\hline 6 & $\mathrm{CH}_{3} \mathrm{CN}$ & 1.3 & $\mathrm{Eu}(\text { fod })_{3}$ & 12 & $60 / 40$ & 70 \\
\hline 7 & $\mathrm{CH}_{3} \mathrm{NO}_{2}$ & 6 & $\mathrm{Eu}(\text { fod })_{3}$ & 1 & $50 / 50$ & 62 \\
\hline 8 & $\mathrm{CH}_{3} \mathrm{NO}_{2}$ & 2 & $\mathrm{Eu}(\text { fod })_{3}$ & 1 & $40 / 60$ & 30 \\
\hline 9 & $\mathrm{CH}_{3} \mathrm{CN}$ & 6 & $\mathrm{ZnBr}_{2}$ & 1 & $25 / 75^{\mathrm{d}}$ & 31 \\
\hline 10 & $\mathrm{CH}_{3} \mathrm{CN}$ & 2.4 & $\mathrm{ZnBr}_{2}$ & 1 & $20 / 80$ & 22 \\
\hline 12 & $\mathrm{CH}_{3} \mathrm{NO}_{2}$ & 6 & $\mathrm{ZnBr}_{2}$ & 1 & $33 / 67^{\mathrm{d}}$ & 25 \\
\hline
\end{tabular}

${ }^{a}$ Determined by integration of well separated signals on the ${ }^{1} \mathrm{H}$ NMR spectra of reaction crudes.

${ }^{\mathrm{b}}$ Mixture of $\mathbf{2 a}$ and $\mathbf{2 b}$ after flash chromatography.

${ }^{\mathrm{c}}$ Not determined.

${ }^{\mathrm{d}}$ Obtained with variable amounts of unknown impurities.

As we could not separate diastereoisomers $\mathbf{2} \mathbf{a}$ and $\mathbf{2} \mathbf{b}$, in order to assign the configuration of the obtained cyclopropanes, the 60:40 mixture of $\mathbf{2 a}$ and $\mathbf{2 b}$ was oxidized with m-CPBA (Scheme 1). The signals corresponding to only one sulfone 3 could be detected in the ${ }^{1} \mathrm{H}$ NMR spectrum of the reaction crude. It means that the oxidation of the diastereomeric sulfoxides $2 \mathbf{a}$ and $\mathbf{2} \mathbf{b}$ yields enantiomeric sulfones $\mathbf{3 a}$ and $\mathbf{3 b}$ (thus exhibiting the same ${ }^{1} \mathrm{H}$ NMR spectrum). Therefore we can conclude that $\mathbf{2} \mathbf{a}$ and $\mathbf{2} \mathbf{b}$ differ in the configuration of their three chiral carbons (they have the same configuration at the sulfinyl sulfur). Then, we established from NMR studies mainly by the two-dimensional NOESY spectrum, that both, $\mathbf{2 a}$ and $\mathbf{2 b}$, have a cis-relationship between their cyclopropanic protons as well as between the olefinic proton at C-3 and the acetalic one. ${ }^{11}$ It restricted the structural possibilities for $\mathbf{2 a}$ and $\mathbf{2} \mathbf{b}$ to those indicated in Table 1. The absolute configuration of $\mathbf{2 a}$ was unequivocally established by chemical correlation with hydrazone 4a (Scheme 1) whose X-ray crystallographic analysis is presented in Fig. 1. 


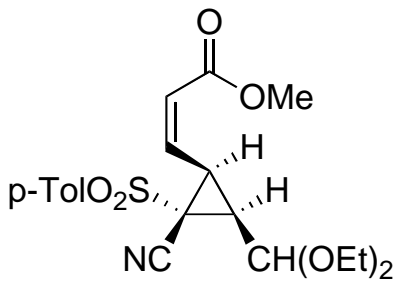

3a

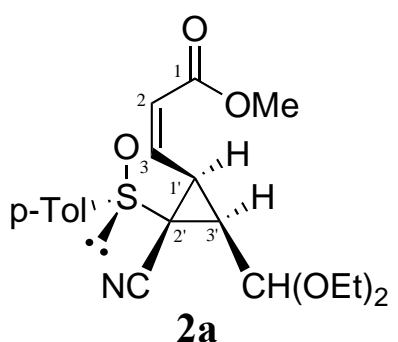

2a

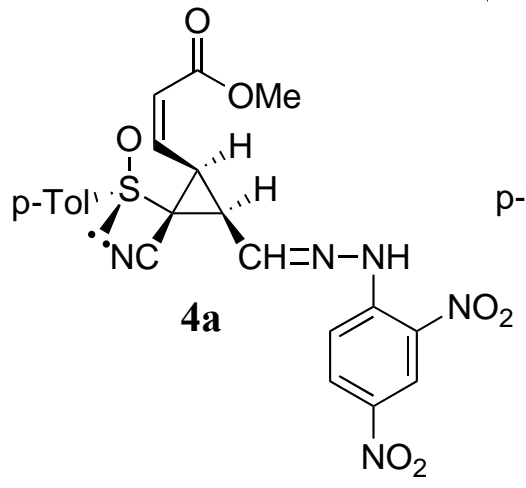

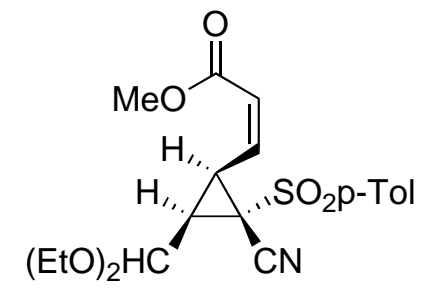

3b

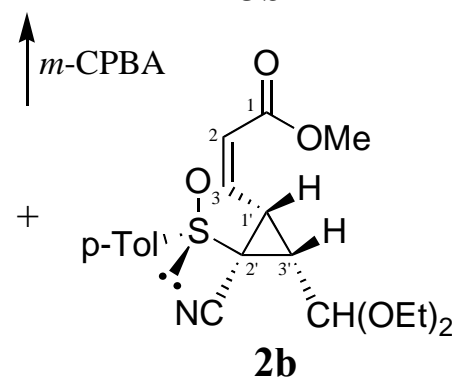

1. $\mathrm{HCOOH}$

2. 2,4-Dinitrophenylhydrazine

3. Fractional crystallization

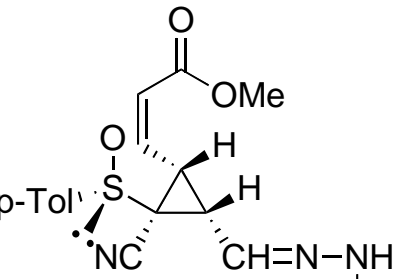

$4 b$<smiles>Nc1ccc([N+](=O)[O-])cc1[N+](=O)[O-]</smiles>

\section{Scheme 1}

This correlation was made by hydrolysis of the mixture of $\mathbf{2} \mathbf{a}$ and $\mathbf{2} \mathbf{b}$ with an excess of 98\% formic acid, which affords a 60:40 mixture of the corresponding cyclopropylaldehydes, which could not be separated. The treatment of this mixture with 2,4-dinitrophenylhydrazine in aqueous acetic acid gave a 60:40 mixture of 2,4-dinitrophenylhydrazones $\mathbf{4 a}$ and $\mathbf{4 b}$, from which the major diasteroisomeric hydrazone 4a was obtained in a pure form by fractional crystallization from $\mathrm{CH}_{2} \mathrm{Cl}_{2}$-hexane. The absolute configuration of $\mathbf{4 a}$ was established as 1'S, $2^{\prime} R$, 3'S, SS by X-ray diffraction analysis ${ }^{12}$ (an ORTEP-type view of $\mathbf{4 a}$ is depicted in Fig. 1). Consequently this must also be the configuration of $\mathbf{2 a}$ and therefore the 1'R, 2' $S$, 3'R, SS configuration must be assigned to $\mathbf{2} \mathbf{b}$.

The stereochemistry of the cyclopropanation reaction must be defined in the first step (Michael-type reaction) giving zwitterionic intermediates $\mathbf{A}^{\prime}$ ' and $\mathbf{B}$ ' which undergo ring closure through stereoselective intramolecular nucleophilic substitution with simultaneous opening of 
the heterocyclic ring affording $\mathbf{2 a}$ and $\mathbf{2 b}$, respectively ${ }^{9}$ (Scheme 2). The stereoselectivity under different conditions can be rationalized taking into account a sterically favored approach of

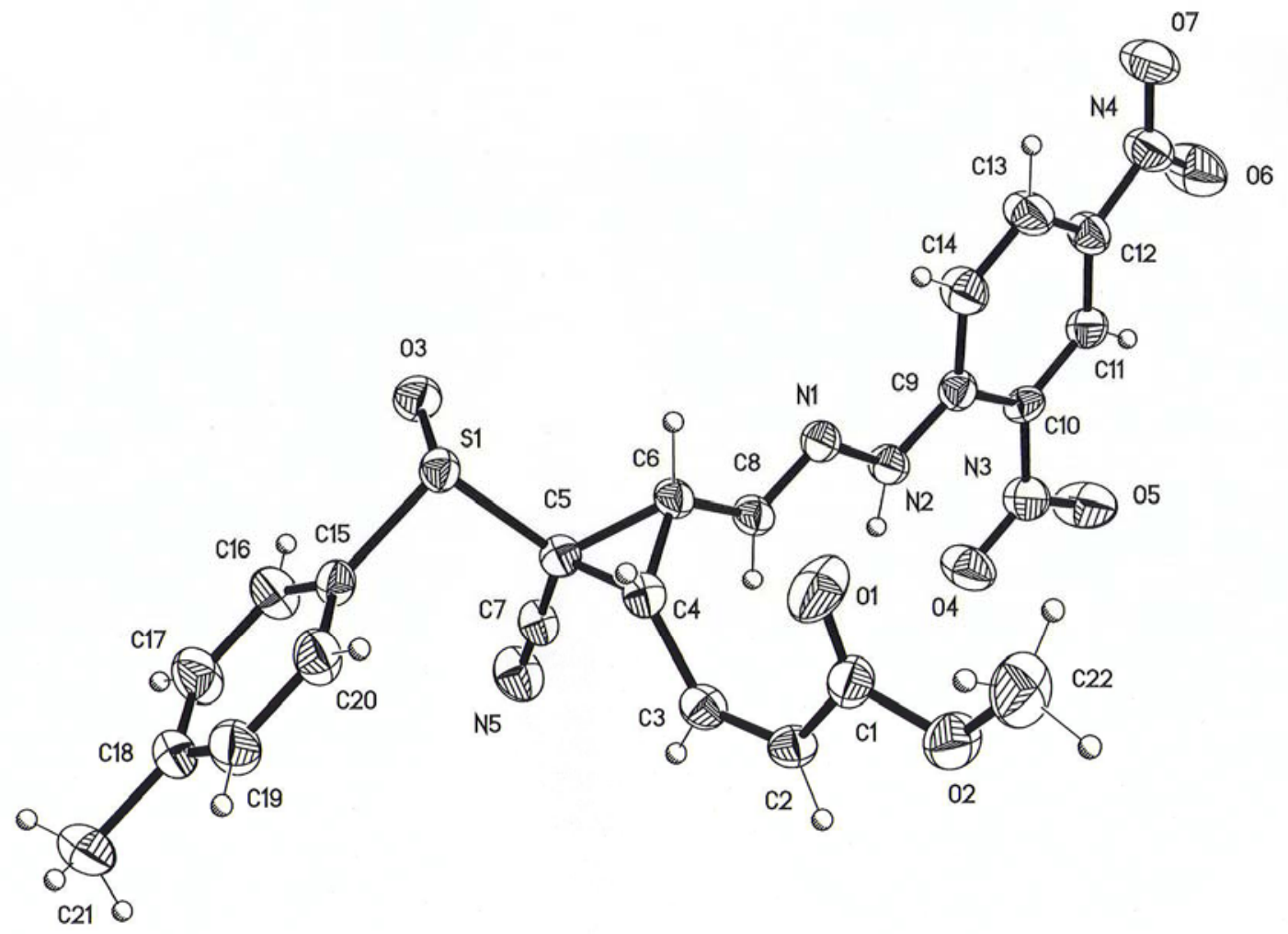

Figure 1. X-Ray structure for hydrazone $\mathbf{4 a}$.

2-methoxyfuran to vinyl sulfoxide 1 from the less hindered face which supports the lone electron pair at the sulfur atom. The presumably most stable conformations around the C-S bond for vinyl sulfoxides must be $\mathbf{A}$ and $\mathbf{B}$, with the sulfinyl oxygen adopting the s-cis and s-trans arrangement with respect to the double bond. Rotamer A should be slightly favored from electrostatic grounds (dipolar repulsion of the $\mathrm{CN}$ and SO bonds) and therefore, the compound resulting in the approach of the nucleophile to the less hindered face of the $\mathbf{A}$ conformation (bottom face in Scheme 2) must be the major one. Two possible transition states can be postulated: TS I and TS III differing at the nucleophilic atom adopting the antiperiplanar relationship with respect to the electrophilic $\mathrm{C}=\mathrm{C}(\mathrm{C}$ and $\mathrm{O}$, respectively), being the first one the most stable. It would explain the formation of $\mathbf{A}^{\prime}$ and therefore $\mathbf{2 a}$ as the major isomer. The compound resulting from the evolution of TS III is not observed in the reaction. The attack of the nucleophile to conformation $\mathbf{B}$ would result in the formation of $\mathbf{2 b}$ through TS II and the intermediate B'. The fact that the observed de decreases in a more polar solvent could be a consequence of their influence on the composition of the conformational equilibrium around the C-S bond (A rotamer is less polar than $\mathbf{B}$ rotamer) and the inversion of the stereoselectivity 
produced by the addition of Eu(fod) $)_{3}$ could be explained by assuming that its association with the sulfinyl oxygen (the presumably most basic center at the substrate) destabilize TSI more than TSII (Scheme 2).

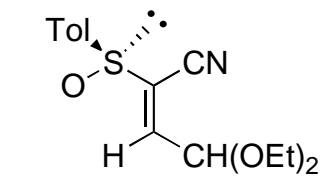

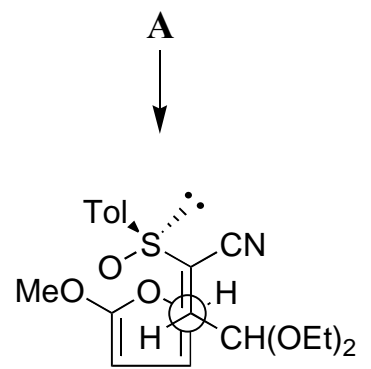

TS I

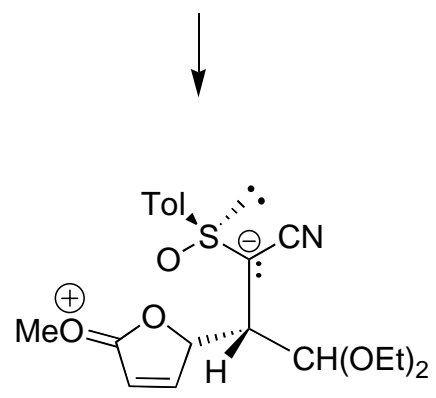

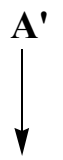

2a
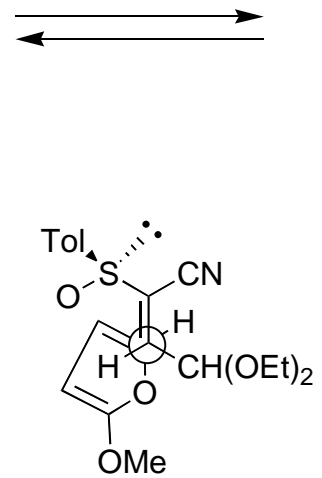

TS III<smiles>CCOCC1C=CC(C#N)=C1O</smiles>

B

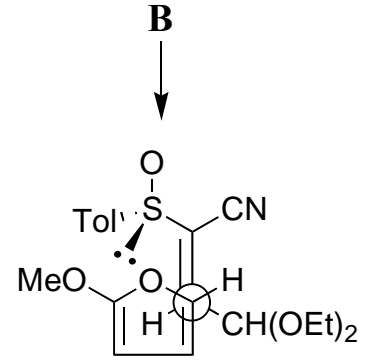

TS II

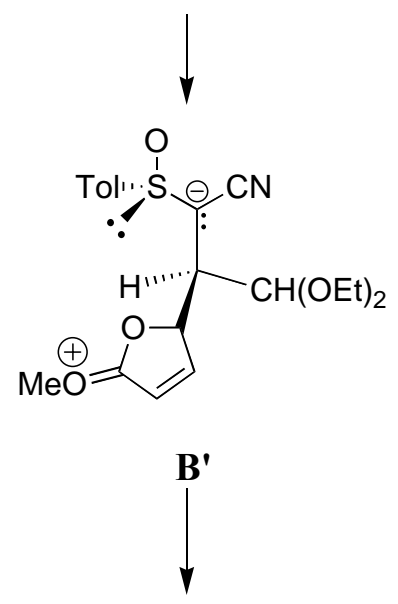

2b

\section{Scheme 2}

Finally, the desulfinylation of $\mathbf{2 a}$ and $\mathbf{2 b}$ was investigated. Reductive desulfinylation was attempted with several reagents, namely, Raney nickel, sodium or aluminum amalgam, samarium iodide and $\mathrm{Zn} / \mathrm{NH}_{4} \mathrm{Cl}$. In all cases, these reactions were unsuccessful. However, desulfinylation of a 60:40 mixture of $\mathbf{2 a}$ and $\mathbf{2 b}$ was carried out with 5 equiv. of $\mathrm{EtMgBr}^{13}$ in THF at $-78^{\circ} \mathrm{C}$ and trapping of the resulting Grignard intermediate $(\mathbf{C})$ with an excess of saturated ammonium chloride solution. Purification by flash column chromatography gave a 60:40 mixture of diastereoisomeric cyclopropanes $\mathbf{5}$ and $\mathbf{6}$ which suggests that desulfinylation has not taken place with complete stereoselectivity (Scheme 3), but with epimerization at the carbon supporting the sulfur function, thus yielding $\mathbf{C}$ and $\mathbf{C}$ ' in a 60:40 mixture (Scheme 3) which was 
subsequently protonated. On preparative thin-layer chromatography the 60:40 mixture of cyclopropanes $\mathbf{5}$ and $\mathbf{6}$ could be separated. The cis arrangement of the three protons at cyclopropane $\mathbf{5}$ was unequivocally established by NOESY studies. The NOESY spectrum of $\mathbf{5}$ showed proximity between H-1', H-2' and H-3' (Scheme 3). Afterwards we performed the capture of the Grignard intermediates $\mathbf{C}$ and $\mathbf{C}^{\prime}$ (generated with 5 equiv. of EtMgBr) with iodomethane (7 equiv.) affording a 1:1 mixture of cyclopropane 5 and methylcyclopropane 7, both obtained as a 60:40 mixture of their enantiomers as it could be established by ${ }^{1} \mathrm{H}$ NMR by using $\mathrm{Yb}(\mathrm{hfc})_{3}$ as chiral shift reagent. The NOESY spectrum of 7 showed the methyl group at C2' close in the space to H-1'and H-3'. The use of larger amounts of MeI does not increase the proportion of $\mathbf{7}$ in the mixture. These results suggest that only the intermediate $\mathbf{C}$ evolves in the methylation process, which takes place with retention of the configuration. The lack of reactivity of $\mathbf{C}^{\prime}$ could be due to steric reasons (the substituents at the C-1 and C-3 are oriented toward the approach direction of the electrophile).

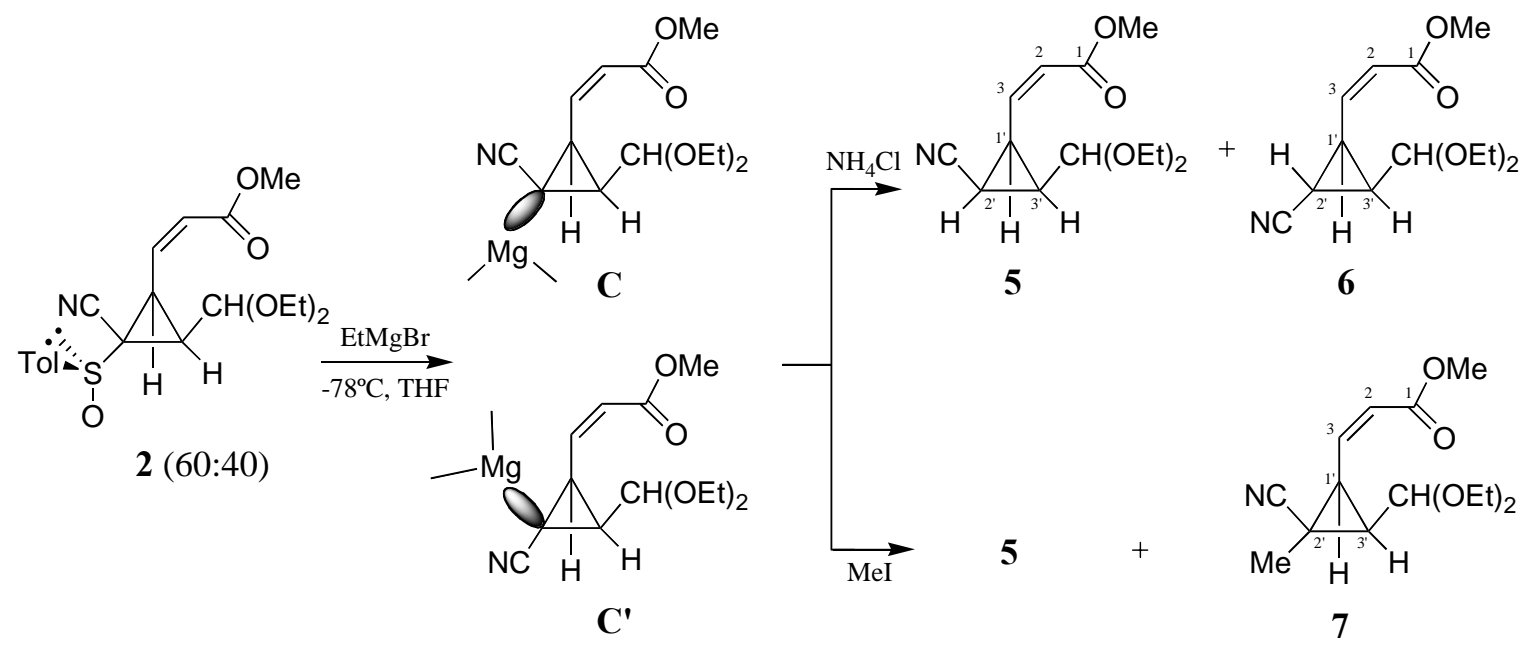

Scheme 3

In conclusion, we have demonstrated that 2-methoxyfuran acts as a nucleophile in its reaction with 2-sulfinylacrylonitrile $\mathbf{1}$ providing a new access to the asymmetric synthesis of cyclopropanes. The 2-sulfinylacrylonitrile 1 reacts with moderated selectivity yielding a mixture of two diastereoisomers whose separation is not possible, which restricts the usefulness of the reaction. The search of new vinylsulfoxides able to evolve in a more stereoselective way is in progress.

\section{Experimental Section}

General Procedures. All moisture sensitive reactions were carried out in a flame dried glassware under argon atmosphere and monitored by TLC. Flash chromatography was performed with silica gel 60 (230-400 mesh ASTM). Melting points were determined in a Culatti melting 
point apparatus in open capillary tubes and are uncorrected. The optical rotations were measured at room temperature $\left(20-23{ }^{\circ} \mathrm{C}\right)$ using a Perkin-Elmer 343 polarimeter (concentration in $\mathrm{g} / 100 \mathrm{~mL}$ ). The IR spectra were recorded in a Nicolet-5SX spectrophotometer. The NMR spectra were determined in $\mathrm{CDCl}_{3}$ solutions unless otherwise indicated at 300 and $75.5 \mathrm{MHz}$ for ${ }^{1} \mathrm{H}$ and ${ }^{13} \mathrm{C}-\mathrm{NMR}$, respectively. Chemical shifts $(\delta)$ are reported in ppm and $J$ values are given in hertz. Mass spectra were measured at $70 \mathrm{eV}$ and $190^{\circ} \mathrm{C}$. All described compounds were over $97 \%$ pure by NMR analysis.

Methyl (2Z,1'S,2'R,3'S,Ss)-3-[2'-cyano-3'-diethoxymethyl-2'-[(4-methylphenyl)sulfinyl]cyclopropyl]acrylate (2a) and methyl $\left(2 Z, 1^{\prime} R, 2^{\prime} S, 3 ' R, S s\right)-3-\left[2^{\prime}\right.$-cyano-3'-diethoxymethyl-2'-[(4methylphenyl)sulfinyl]-cyclopropyl]acrylate (2b)

Method A. Thermal conditions. To a solution of $\mathbf{1}^{10 \mathrm{e}}(0.10 \mathrm{~g}, 0.34 \mathrm{mmol}, 1$ equiv. $)$ in $5 \mathrm{~mL}$ of the solvent, 2-methoxyfuran was added (solvents and equiv. of 2-methoxyfuran indicated in Table 1). The reaction mixture was stirred at room temperature for the time indicated in Table 1. Water $(5 \mathrm{~mL})$ was added and the mixture was extracted with $\mathrm{CH}_{2} \mathrm{Cl}_{2}(3 \times 10 \mathrm{~mL})$ The organic layer was dried $\left(\mathrm{Na}_{2} \mathrm{SO}_{4}\right)$ and evaporated. The crude product was purified by flash chromatography (hexane-ethyl acetate 80:20).

Method B. In the presence of Lewis acids. A solution of $\mathbf{1}^{10 \mathrm{e}}(0.10 \mathrm{~g}, 0.34 \mathrm{mmol}, 1$ equiv.) and Lewis acid (1.5 equiv.) in $7 \mathrm{~mL}$ of the solvent was stirred at room temperature for $1 \mathrm{~h}$ (solvents and Lewis acids indicated in Table 1). Then 2-methoxyfuran was added and the reaction mixture was stirred at room temperature (equiv. and times indicated in Table 1). Water $(10 \mathrm{~mL})$ and $\mathrm{CH}_{2} \mathrm{Cl}_{2}(10 \mathrm{~mL})$ were added. The aqueous phase was separated and extracted with $\mathrm{CH}_{2} \mathrm{Cl}_{2}$ $(3 \times 10 \mathrm{~mL})$ The combined organic fractions were dried $\left(\mathrm{Na}_{2} \mathrm{SO}_{4}\right)$ and evaporated. The crude product was purified by flash chromatography (hexane-ethyl acetate 80:20). The adducts $\mathbf{2 a}$ and 2b were obtained as an inseparable mixture in the diastereoisomeric ratios and yields indicated in Table 1. Yellow oil; IR $\left(\mathrm{CHCl}_{3}\right)$ vmax: 2981, 2235, 1719, $1443 \mathrm{~cm}^{-1} ;{ }^{1} \mathrm{H} \mathrm{NMR}\left(\mathrm{CDCl}_{3}\right.$, $300 \mathrm{MHz}$ ): $2 \mathrm{a} \delta 0.99$ (t, 3H, $J$ 7.2), 1.17 (t, 3H, $J$ 7.2), 2.43 (s, 3H), 2.57 (dd, 1H, $J 6.9$ and 10.2), 3.25 (qd, 1H, $J 7.2$ and 9.3), 3.43-3.60 (m, 3H), 3.62-3.77 (m, 1H), 3.79 (s, 3H), 4.53 (d, 1H, $J$ 7.2), 6.11 (d, $1 \mathrm{H}, J$ 11.4), 6.19 (dd, $1 \mathrm{H}, J 8.1$ and 11.4 ), 7.36 and 7.65 (AA'BB' system, $4 \mathrm{H}$ ); ${ }^{13} \mathrm{C}$ NMR (CDCl 35 MHz): $\delta 15.0$ (2C), 21.5, 25.8, 27.5, 41.3, 51.6, 60.9, 62.5, 98.2, 113.7, 124.8, 125.1, 129.9, 137.5, 138.1, 143.3, 165.8; 2 b $\delta 1.14$ (t, 3H, J 7.2), 1.14 (t, 3H, J 7.2), 2.42 (s, 3H), 2.46 (dd, 1H, $J 6.9$ and 10.2), 3.43-3.74 (m, 4H), 3.78 (s, 3H), 4.18 (dd, 1H, J 9.0 and 10.2), 4.68 (d, 1H, $J$ 7.2), 5.98 (d, 1H, $J$ 11.4), 6.05 (dd, 1H, $J 9.0$ and 11.4), 7.36 and 7.65 (AA'BB' system, $4 \mathrm{H}) ;{ }^{13} \mathrm{C} \mathrm{NMR}\left(\mathrm{CDCl}_{3}, 75 \mathrm{MHz}\right): \delta 14.8$ (2C), 21.5, 22.9, 32.0, 42.2, 51.5, 60.8, 62.6, 98.0, 113.3, 124.3, 124.8, 129.9, 137.2, 138.3, 143.3, 165.8; EIMS m/z 391 (0.3\%, M ), 252 (54), 220 (34), 192 (46), 164 (69), 139 (100), 103 (25). Anal. Calcd. for $\mathrm{C}_{20} \mathrm{H}_{25} \mathrm{NO}_{5} \mathrm{~S}$ : C, 61.36; H, 6.44; N, 3.58; S, 8.19. Found: C, 61.66; H, 6.35; N, 3.50, S, 8.02.

Methyl (2Z,1'S,2'R,3'S)-3-[2'-cyano-3'-diethoxymethyl-2'-[(4-methylphenyl)sulfonyl]cyclopropyl]-acrylate (3a) and methyl $\left(2 Z, 1^{\prime} R, 2^{\prime} S, 3 ' R\right)-3-\left[2^{\prime}\right.$-cyano-3'-diethoxymethyl-2'-[(4methylphenyl)sulfonyl]-cyclopropyl]acrylate (3b). To a stirred solution of a mixture of $\mathbf{2 a}$ and 
2b (0.10 g, $0.255 \mathrm{mmol})$ in $10 \mathrm{~mL}$ of $\mathrm{CH}_{2} \mathrm{Cl}_{2} \mathrm{~m}$-CPBA (0.082 g, $\left.0.38 \mathrm{mmol}\right)$ was added at room temperature. The reaction mixture was stirred for $15 \mathrm{~h}$. A $10 \%$ aqueous $\mathrm{NaHCO}_{3}(10 \mathrm{~mL})$ was added. The aqueous phase was separated and extracted with $\mathrm{CH}_{2} \mathrm{Cl}_{2}(3 \times 10 \mathrm{~mL})$ The combined organic fractions were dried $\left(\mathrm{Na}_{2} \mathrm{SO}_{4}\right)$ and evaporated (yield 98\%, colorless oil). IR $\left(\mathrm{CHCl}_{3}\right)$

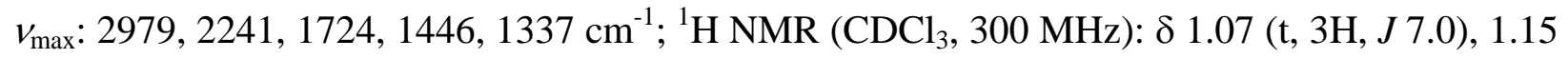
(t, 3H, J 7.0), 2.47 (s, 3H), 2.72 (dd, $1 \mathrm{H}, J 7.0$ and 10.5), 3.41 (qd, 1H, $J 7.0$ and 9.0), 3.50-3.67 (m, 3H), 3.79 (s, 3H), 4.28 (dd, 1H, $J 8.1$ and 10.5), 4.57 (d, 1H, $J$ 7.0) 6.04 (dd, $1 \mathrm{H}, J 8.1$ and 11.4), 6.10 (d, $1 \mathrm{H}, J$ 11.4), 7.39 and 7.88 (AA'BB' system, $4 \mathrm{H}) ;{ }^{13} \mathrm{C}$ NMR $\left(\mathrm{CDCl}_{3}, 75 \mathrm{MHz}\right.$ ): $\delta$ 14.9 (2C), 21.7, 28.4, 34.4, 43.5, 51.6, 61.3, 62.6, 97.8, 112.7, 125.6, 129.1, 130.0, 133.7, 136.8, 146.1, 165.6; EIMS m/z 407 (not observed, $\mathrm{M}^{+}$), 376 (3), 362 (25), 252 (36), 206 (26), 155 (45), 143 (49), 103 (100), 91 (87).

Methyl $\quad\left(2 Z, 1^{\prime} S, 2^{\prime} R, 3 ' S, S s\right)-3-\left[2^{\prime}\right.$-cyano-3'-[(2,4-dinitrophenyl)hydrazonomethyl]-2'-[(4methyl- phenyl)sulfinyl]-cyclopropyl]acrylate (4a). To a 60:40 mixture of $\mathbf{2 a}$ and $\mathbf{2 b}(0.029$ g, $0.074 \mathrm{mmol})$ an excess of $98 \%$ formic acid $(0.17 \mathrm{~g}, 0.14 \mathrm{~mL}, 3.7 \mathrm{mmol})$ was added. The reaction mixture was left on standing at room temperature for $0.5 \mathrm{~h}$. Water $(5 \mathrm{~mL})$ and $\mathrm{CH}_{2} \mathrm{Cl}_{2}(5 \mathrm{~mL})$ were added. The organic phase was washed with a $10 \%$ aqueous $\mathrm{NaHCO}_{3}(5 \mathrm{~mL})$, dried $\left(\mathrm{Na}_{2} \mathrm{SO}_{4}\right)$ and concentrated to give $0.023 \mathrm{~g}(98 \%$,) of a 60:40 mixture of the corresponding crude aldehydes, as a yellow oil. Without further purification, to this crude product dissolved in ethanol $(1 \mathrm{~mL})$ an excess of a solution of 2,4-dinitrophenylhydrazine in acetic acid was added. After 15 min the resulting solid was filtered and washed with ethanol. ${ }^{1} \mathrm{H}$ NMR analysis of this product shows that it was a 60:40 mixture of $\mathbf{4 a}$ and $\mathbf{4 b}$. Recrystallization from $\mathrm{CH}_{2} \mathrm{Cl}_{2} /$ hexane produced $0.010 \mathrm{~g}(27 \%)$ of $\mathbf{4 a}$ as yellow crystals, $\mathrm{mp} 162-5^{\circ} \mathrm{C}$ (decomp.). $[\alpha]_{\mathrm{D}}+24.0$ (c 0.5, $\mathrm{CHCl}_{3}$ ); IR $\left(\mathrm{CHCl}_{3}\right) v_{\text {max }}: 3302,3105,2025,1948,1720,1617,1395,1339 \mathrm{~cm}^{-1} ;{ }^{1} \mathrm{H}$ NMR $\left(\mathrm{CDCl}_{3}, 300\right.$ $\mathrm{MHz}$ ): $\delta 2.43$ (s, 3H), 3.26 (dd, 1H, J 6.4 and 10.0), 3.81 (s, 3H), 4.10 (ddd, $1 \mathrm{H}, J 3.2$, 4.1 and 10.0), 6.20 (d, 1H, J 11.4), 6.23 (dd, 1H, J 4.1 and 11.4), 7.37 (d, 1H, J 3.2), 7.39 and 7.67 (AA'BB' system, 4H), 7.83 (d, 1H, J 9.6), 8.34 (dd, 1H, $J 2.6$ and 9.6), 9.09 (d, 1H, $J$ 2.6), 11.17 (s, $1 \mathrm{H}) ;{ }^{13} \mathrm{C} \mathrm{NMR}\left(\mathrm{CDCl}_{3}, 75 \mathrm{MHz}\right): \delta 21.6,26.0,28.1,43.9,51.8,113.2,116.7,123.1,124.5$, 126.3, 129.6, 130.2, 130.3, 136.3, 137.1, 138.9, 140.3, 144.0, 144.3, 165.6. MS (FAB $\left.{ }^{+}\right) \mathrm{m} / \mathrm{z} 498$ (12\%, M+1), 307 (39), 289 (22), 155 (39), 154 (99), 138 (43), 137 (84), 136 (100), 107 (33), 89 (32), 77 (30). Anal. Calcd. for $\mathrm{C}_{22} \mathrm{H}_{19} \mathrm{~N}_{5} \mathrm{O}_{7} \mathrm{~S}$ : C, 53.11; H, 3.85; N, 14.08; S, 6.45. Found: C, 53.19; H, 3.72; N, 14.37, S, 6.32.

Methyl $\left(2 Z, 1^{\prime} S^{*}, 2^{\prime} R^{*}, 3^{\prime} S^{*}\right)-3-\left[2^{\prime}\right.$-cyano-3'-diethoxymethyl-cyclopropyl]acrylate (5) and methyl $\left(2 Z, 1^{\prime} S^{*}, 2^{\prime} S^{*}, 3^{\prime} S^{*}\right)-3$-[2'-cyano-3'-diethoxymethyl-cyclopropyl]acrylate (6). To a solution of EtMgBr (5 equiv.) in $5 \mathrm{~mL}$ of $\mathrm{THF}$ at $-78^{\circ} \mathrm{C}$ a solution of $\mathbf{2 a}$ and $\mathbf{2 b}(60: 40)(0.10 \mathrm{~g}$, $0.255 \mathrm{mmol})$ in $3 \mathrm{~mL}$ of THF was added. After $5 \mathrm{~min}$, a saturated solution of $\mathrm{NH}_{4} \mathrm{Cl}(5 \mathrm{~mL})$ was added. The organic phase was separated and the aqueous phase was extracted with $\mathrm{CH}_{2} \mathrm{Cl}_{2}$ $(3 x 5 \mathrm{~mL})$. The combined organic layers were dried and concentrated. The residue was purified by column chromatography eluting with hexane-ethyl acetate $70: 30$ to produce $0.040 \mathrm{~g}(61 \%)$ of a 60:40 mixture of $\mathbf{5}$ and $\mathbf{6}$. Further purification by preparative thin layer chromatography gave $0.018 \mathrm{~g}$ (28\%) of 5 and $0.012 \mathrm{~g}(18 \%)$ of $\mathbf{6}$ both as a yellow oils; Compound 5: IR $\left(\mathrm{CHCl}_{3}\right) v_{\text {max }}$ : 
2978, 2238, 1720, 1643, $1446 \mathrm{~cm}^{-1} ;{ }^{1} \mathrm{H} \mathrm{NMR}\left(\mathrm{CDCl}_{3}, 300 \mathrm{MHz}\right): \delta 1.17(\mathrm{t}, 3 \mathrm{H}, J$ 7.0), $1.26(\mathrm{t}$, 3H, $J$ 7.0), 2.00 (ddd, 1H, $J$ 7.5, 8.7 and 9.3), 2.10 (dd, 1H, $J$ 8.4), 3.50 (dd, $1 \mathrm{H}, J 8.7$ and 9.3), 3.53-3.82 (m, 4H), 3.75 (s, 3H), 4.62 (d, 1H, J 7.6), 6.08 (d, 1H, J 11.7), 6.17 (dd, 1H, J 9.6 and

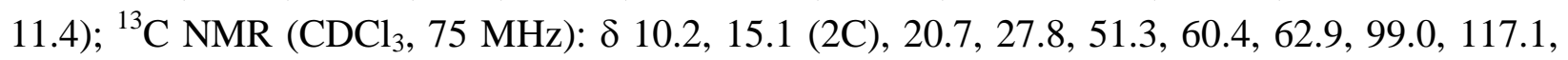
123.4, 141.5, 166.3; EIMS m/z 253 (not observed, $\mathrm{M}^{+}$), 222 (5), 208 (49),143 (17), 124 (19), 110 (100), 103 (37), 98 (37), 82 (36). Anal. Calcd. for $\mathrm{C}_{13} \mathrm{H}_{19} \mathrm{NO}_{4}$ : C, 61.64; H, 7.56; N, 5.53. Found: C, 61.79; H, 7.40; N, 5.35. Compound 6: ${ }^{1} \mathrm{H}$ NMR $\left(\mathrm{CDCl}_{3}, 300 \mathrm{MHz}\right): \delta 1.18$ (t, 3H, J 7.3), 1.21 (t, 3H, J 7.3), 1.89 (dd, 1H, $J$ 5.5), 2.09 (ddd, 1H, J 3.2, 5.5 and 9.6), 3.42-3.80 (m, 5H), 3.75 (s, 3H), 4.66 (d, $1 \mathrm{H}, J$ 3.2), 5.91 (d, $1 \mathrm{H}, J 11.7), 5.98$ (dd, $1 \mathrm{H}, J 8.8$ and 11.4$) ;{ }^{13} \mathrm{C} \mathrm{NMR}\left(\mathrm{CDCl}_{3}, 75\right.$ MHz): $\delta$ 9.2, 15.2 (2C), 23.7, 29.7, 51.4, 60.4, 62.0, 97.4, 119.7, 122.4, 143.1, 166.4; Anal. Calcd. for $\mathrm{C}_{13} \mathrm{H}_{19} \mathrm{NO}_{4}$ : C, 61.64; H, 7.56; N, 5.53. Found: C, 61.70; H, 7.27; N, 5.40.

Methyl $\left(2 Z, 1^{\prime} S^{*}, 2^{\prime} R^{*}, 3^{\prime} S^{*}\right)-3-\left[2^{\prime}\right.$-cyano-3'-diethoxymethyl-2'-methyl-cyclopropyl]acrylate (7). To a solution of EtMgBr (3.5 equiv.) in $5 \mathrm{~mL}$ of $\mathrm{THF}$ at $-78^{\circ} \mathrm{C}$ a solution of $\mathbf{2 a}$ and $\mathbf{2 b}$ (60:40)(0.10 g, $0.255 \mathrm{mmol})$ in $3 \mathrm{~mL}$ of THF was added. After $5 \mathrm{~min}$, was added methyl iodide $\left(0.111 \mathrm{~mL}, 1.79 \mathrm{mmol}, 7\right.$ equiv.) and the resulting solution stirred at $-78^{\circ} \mathrm{C}$ for $30 \mathrm{~min}$. Then, a saturated solution of $\mathrm{NH}_{4} \mathrm{Cl}(5 \mathrm{~mL})$ was added. The organic phase was separated and the aqueous phase was extracted with $\mathrm{CH}_{2} \mathrm{Cl}_{2}(3 \times 5 \mathrm{~mL})$. The combined organic layers were dried and concentrated. The residue was purified by column chromatography eluting with hexane-ethyl acetate 70:30 to produce $0.023 \mathrm{~g}$ (33\%,) of 7 (ee 20\%, determined by ${ }^{1} \mathrm{H}$ NMR by using $\mathrm{Yb}(\mathrm{hfc})_{3}$ as chiral shift reagent) as a yellow oil and $0.020 \mathrm{~g}(32 \%)$ of 5; Compound 7: IR $\left(\mathrm{CHCl}_{3}\right) v_{\text {max }}$ : 2977, 2237, 1721, 1641, $1447 \mathrm{~cm}^{-1} ;{ }^{1} \mathrm{H} \mathrm{NMR}\left(\mathrm{CDCl}_{3}, 300 \mathrm{MHz}\right): \delta 1.16$ (t, 3H, J 7.0), 1.26 (t, $3 \mathrm{H}, J$ 7.0), 1.52 (s, 3H), 1.78 (dd, 1H, $J 8.1$ and 9.3), 3.24 (t, 1H, J 9.3), 3.49-3.80 (m, 4H), 3.74 (s, 3H), 4.58 (d, 1H, J 7.9), 6.04 (d, $1 \mathrm{H}, J 11.1), 6.14$ (dd, $1 \mathrm{H}, J 9.6$ and 11.1$) ;{ }^{13} \mathrm{C} \mathrm{NMR}\left(\mathrm{CDCl}_{3}\right.$, $75 \mathrm{MHz}$ ): $\delta$ 15.1, 15.2, 18.3, 21.7, 28.4, 35.5, 51.3, 60.2, 62.8, 99.4, 119.6, 122.7, 142.3, 166.5; EIMS m/z 267 (not observed, $\mathrm{M}^{+}$), 222 (15), 143 (19), 124 (100), 116 (37), 98 (68), 96 (41), 75 (50). Anal. Calcd. for $\mathrm{C}_{14} \mathrm{H}_{21} \mathrm{NO}_{4}$ : C, 62.90; H, 7.92; N, 5.24. Found: C, 62.73; H, 7.80; N, 5.33.

\section{Acknowledgements}

We thank M. I. Chávez, E. Huerta, R. Patiño. M. A. Peña, J. Pérez, H. Ríos, R. A. Toscano, L. Velasco and M. N. Zavala for their technical assistance. Financial support from Consejo Nacional de Ciencia y Tecnología, Conacyt-México (41662-Q) and Dirección de Investigación Científica y Técnica CAICYT (BQU2003-04012) from Spain, is gratefully acknowledged.

\section{References and Footnotes}

1. (a) Lebel, H.; Marcoux, J. -F.; Molinaro, C.; Charette, A. B. Chem. Rev. 2003, 103, 977. (b) Doyle, M. P. In Catalytic Asymmetric Synthesis; $2^{\text {nd }}$ Edn, Ojima, I., Ed.; John Wiley \& Sons: New York, 2000, Ch. 5. (c) Doyle, M. P.; Forbes, D. C. Chem. Rev. 1998, 98, 911. 
2. (a) Donaldson, W. A. Tetrahedron 2001, 57, 8589. (b) Salaün, J. In Topics in Current Chemistry: Small Rings Compounds in Organic Synthesis VI; de Meijere, A., Ed.; Springer: Berlin, 2000, pp 1-67. (c) Suckling, C. J. Angew. Chem., Int. Ed. 1988, 27, 537.

3. Salaün, J. Chem. Rev. 1989, 89, 1247.

4. Wong, H. N. C.; Hon, M. -Y.; Tse, C. -W.; Yip, Y. -C; Tanko, J.; Hudlicky, T. Chem. Rev. 1989, 89, 165.

5. (a) Hiroi, K.; Arinaga, Y. Tetrahedron Lett. 1994, 35, 153. (b) Hiroi, K.; Anzai, T.; Ogata, T.; Saito, M. Tetrahedron Lett. 1990, 31, 239. (c) Salaün, J.; Reibig, H. -U. In Topics in Current Chemistry: Small Rings Compounds in Organic Synthesis III; de Meijere, A., Ed.; Springer: Berlin, 1988; pp 1-135. (c) Trost, B. M. In Topics in Current Chemistry: Small Rings Compounds in Organic Synthesis I; de Meijere, A., Ed.; Springer: Berlin, 1986; pp 182.

6. (a) Verhé, R.; de Kimpe, N. In The chemistry of cyclopropyl group; Patai, S.; Rappoport, Z., Eds; Wiley \& Sons: New York, 1987; pp 445-564. (b) Wang, C. -C.; Huang, H. -C.; Reitz, D. B. Org. Prep. Proced. Int. 2002, 34, 271. (c) Takemoto, Y.; Ohra, T.; Sugiyama, K.; Imanishi, T.; Iwata, C. Chem. Pharm. Bull. 1995, 43, 571. (d) Walker, A. J. Tetrahedron: Asymmetry 1992, 3, 961.

7. García Ruano, J. L.; Fajardo, C.; Martín, M. R.; Midura, W.; Mikolajczyk, M. Tetrahedron: Asymmetry 2004, 15, 2475.

8. García Ruano, J. L.; Martín, M. R.; Martín Castro, A. M.; Torrente, E. Org. Lett. (in press).

9. (a) Urrutia-Desmaison, G.; Mloston, G.; Huisgen, R. Tetrahedron Lett. 1994, 35, 4977. (b) Mloston, G.; Huisgen, R. J. Heterocycl. Chem. 1994, 31, 1279.

10. (a) García Ruano, J. L.; Esteban Gamboa, A.; Martín Castro, A. M.; Rodríguez, J. H.; López-Solera, M. I. J. Org. Chem. 1998, 63, 3324. (b) García Ruano J. L.; Alemparte, C.; Martín Castro, A. M.; Adams, H.; Rodríguez Ramos, J. H. J. Org. Chem. 2000, 65, 7938. (c) García Ruano, J. L.; Alonso de Diego, S. A.; Blanco, D.; Martín Castro, A. M.; Martín, M. R.; Rodríguez Ramos, J. H. Org. Lett. 2001, 3, 3173. (d) Yuste, F.; Ortiz, B.; Pérez, J. I.; Rodríguez-Hernández, A.; Sánchez-Obregón, R.; Walls, F.; García Ruano, J. L. Tetrahedron 2002, 58, 2613. (e) García Ruano, J. L.; González Gutiérrez, L.; Martín Castro, A. M.; Yuste, F. Tetrahedron: Asymmetry 2002, 13, 2003.

11. Strong NOESY correlations were observed between: H-1' $(\delta$ 3.62-3.77)/H-3' $(\delta 2.57)$ and the acetalic proton $(\delta 4.53) / \mathrm{H}-3$ ( $\delta$ 6.19) for 2a; H-1' $(\delta$ 4.18)/H-3' $(\delta 2.46)$ and the acetalic proton $(\delta 4.68) / \mathrm{H}-3(\delta 6.05)$ for $\mathbf{2 b}$.

12. Crystallographic data (excluding structure factors) for $\mathbf{4 a}$ have been deposited with the Cambridge Crystallographic Data Centre as supplementary publication number CCDC 257824. Copies of the data can be obtained, free of charge, on application to CCDC, 12 Union Road, Cambridge CB2 1EZ, UK [fax: +44-(0)1223-336033 or e-mail: deposit@ccdc.cam.ac.uk].

13. Satoh, T.; Sato, T.; Oohara, T.; Yamakawa, K. J. Org. Chem. 1989, 54, 3973. 